\title{
Increasing cut surface quality with various cutting nozzle head oscillations for abrasive aquajet machining
}

\author{
K J Patel ${ }^{1 *}$ and F L Chen ${ }^{2}$ \\ ${ }^{1}$ SITMS, University of Ballarat, Victoria, Australia \\ ${ }^{2}$ IRIS, Swinburne University of Technology, Hawthorn, Victoria, Australia
}

\begin{abstract}
This short paper introduces different nozzle oscillation cutting methods, which are developed using theoretical formulae as well as experimental resources. A comparison study was conducted using different surface texture parameters between a straight cut and different oscillation cutting methods with the same cutting parameters. An optimum oscillation cutting method is suggested. A significant amount of increase in surface quality was obtained.
\end{abstract}

Keywords: nozzle oscillation cutting methods, surface texture parameters, surface quality, abrasive aquajet machining

\section{INTRODUCTION}

The abrasive aquajet (AAJ), mostly known as the abrasive waterjet (AWJ), is now well known as a 'nontraditional' method of machining that offers a productive alternative to conventional techniques. A significant amount of work has been done directly or indirectly on understanding or explaining the striation formation mechanism, since features resulting from the use of traditional machine tools, the surface characteristics resulting from AWJ, are not homogeneous within a certain range and change with cutting parameters. In AWJ machining, shear deformation occurs through microchip formation, ploughing and rubbing and all of these depend on the abrasive attack angle and other mechanical properties [1]. The cutting process is highly dependent on the angle of impact and the rake angle [2]. At the same time they also help in forming striation or reducing it. It is very important to know, taking material thickness into consideration, what the suitable parameters are. The parameters that can be varied, such as pressure, abrasive flowrate, traverse speed and workpiece and cutting machine vibration, affect forming striation. However, among all the factors mentioned above, the important factor that helps strongly in forming striation is the velocity of cutting or the traverse rate of the cutting mechanism [3]. Many aspects about AWJ technology are

The MS was received on 18 March 2003 and was accepted after revision for publication on 28 April 2003.

*Corresponding author: SITMS, University of Ballarat, PO Box 663, Mt Helen, Ballarat, Victoria 3350, Australia. still confusing and need to be investigated in more depth. The slow cutting speed involved needs to be increased without producing an inferior quality of surface finish. A huge amount of effort has been put into explaining how striation is formed and the factors affecting it, but very little work has been done on minimizing [4] or eliminating striation at the cutting capacity of the jet using different techniques of the oscillating nozzle.

This paper deals with the quality of the AWJ cut surface at the cutting capacity of the jet. This can only be proved by comparing the same cutting parameters for a straight cut and an oscillation cut. In this study, work was undertaken to investigate the roughness in the visually seen smooth zone and also in the predefined smooth zone (from 0.02 to $60 \mu \mathrm{m}$ ) for both a straight cut and an oscillation cut. In addition to this, two different oscillation techniques were developed in a very systematic way to enhance the AWJ cutting quality and process potential applications. Both oscillation techniques are very similar but give different results in different directions. A detailed explanation is given for different oscillation cutting techniques.

\section{EXPERIMENTAL PROCEDURE}

A six-degree-of-freedom robot manipulator was used for cutting with the help of a high-pressure intensifier (Fig. 1). An offset of $300 \mathrm{~mm}$ was taken from the $T$ axis of the robot in the $Y+$ direction for ease of oscillation in both directions. 


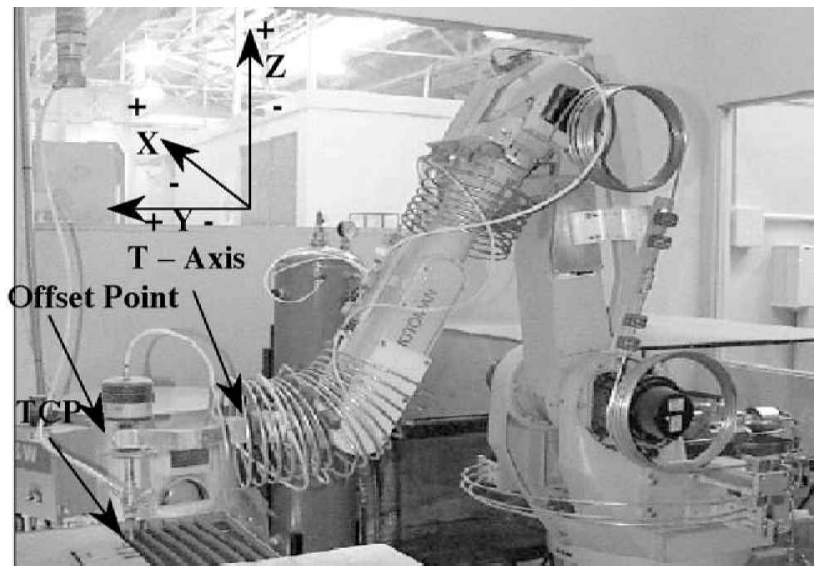

Fig. 1 Five-axis robot manipulator used with a high-pressure intensifier for the cutting experiment

Mild steel (MS) with a thickness of $20 \mathrm{~mm}$ was used as a specimen in the form of a plate. Work done by Siores et al. [1] gives a rough idea that to get the optimum result the oscillation angle should be below $5^{\circ}$ and the oscillation frequency should be between 2 and 5. In order to investigate the AWJ cutting parameters in oscillation cutting, oscillation frequency $(F)$, oscillation angle $(\alpha)$ and incremental distance $(I)$, for cutting of MS, a statistical experimental design scheme requiring 74 (72 oscillation cuts +2 straight cuts) runs was adopted, taking the oscillation frequency from 2 to 5 and the oscillation angle from 2 to $7^{\circ}$. Other cutting parameters were kept constant, such as the abrasive flowrate $\left(f_{\mathrm{a}}=0.36 \mathrm{~kg} / \mathrm{s}\right)$, traverse speed $(V=1 \mathrm{~mm} / \mathrm{s})$, pressure $(P=344.75 \mathrm{MPa}), \quad$ standoff distance $\left(S_{\mathrm{d}}=2 \mathrm{~mm}\right)$, type of abrasive (garnet), its grain size (mesh $80,180 \mu \mathrm{m}$ ) and diameter of the cutting nozzle $\left(D_{\mathrm{n}}=1.33 \mathrm{~mm}\right)$.

\section{BASIC CONCEPT AND DEFINITIONS}

When the jet angle of impact is $90^{\circ}$ to the workpiece and there is no change in the angle, the cutting nozzle traverses further; this type of cutting can be called a straight cut. When the jet angle of impact is varying with respect to the workpiece during continuous traversing of the cutting nozzle, this type of cutting can be called oscillation cutting. The basic concept behind developing the two different oscillation techniques with the help of robot programming is as follows.

The main purpose of programming and formulating an equation for the robot is to compare the oscillation cut with the straight cut using the same parameters. If a straight cut is made only the linear velocity $(V)$ is known, so this $V$ value should be the same as that for the oscillation cut, when keeping all the oscillation parameters in mind. The off-line programming of a robot input $V_{\mathrm{r}}$ (rotational velocity in $\mathrm{deg} / \mathrm{s}$ ), $I$ (incremental distance in $\mathrm{mm}$ ) and $C$ (number of cycles). These can all be calculated using the known input parameters, like $F$ (frequency of
Method-I

Both-side equal incremental move or two-side incremental move

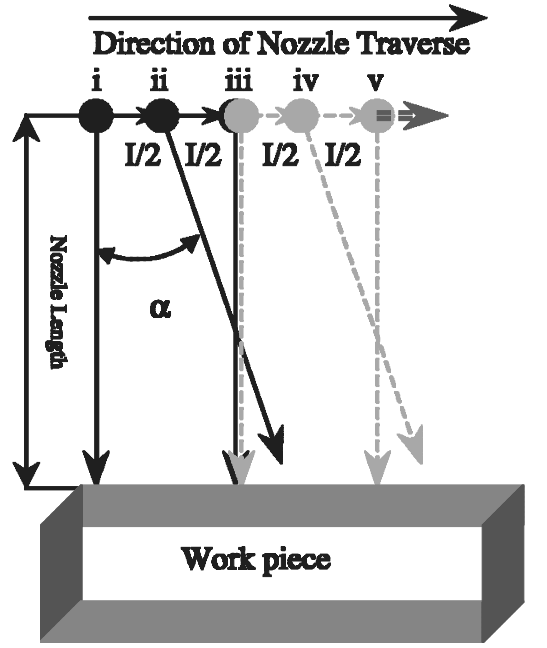

Method - II One-side incremental move
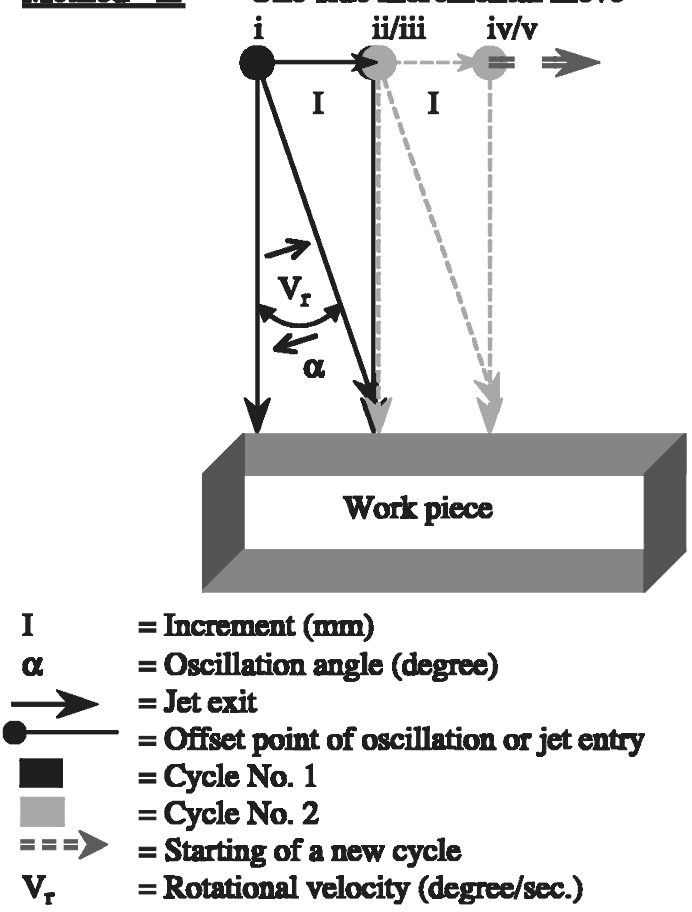

Fig. 2 Schematic of different oscillation techniques

oscillation in cycles/s), $V$ (linear traverse speed in $\mathrm{mm} / \mathrm{s}$ ) and $\alpha$ (oscillation angle in deg). Since these parameters need to be adjusted they were made to be flexible and a subroutine program was developed that calculated $V_{\mathrm{r}}, C$ and $I$.

Method II of Fig. 2 is now considered, where one of the nozzle's ends is hinged and the other is free from where the jet exits (TCP). When point 1 at a certain rotational velocity $\left(V_{\mathrm{r}}\right)$ travels to point 2 with a certain angle $(\alpha)$ it comes back to point 1 . This type of motion is called as one simple oscillation or one cycle without any increment and the total time taken is $t$. The time taken to complete one cycle in the direction of cutting 
or the direction of traverse can then be formulated as follows:

$$
\begin{aligned}
& t=\frac{2 \alpha}{V_{\mathrm{r}}} \\
& V_{\mathrm{r}}=2 \alpha F
\end{aligned}
$$

Now, in order to gain some speed there needs to be some increment in the oscillation motion. When some increment is taken in the direction of cutting it is found to be directly proportional to the linear velocity $(V)$. When the frequency is combined with the velocity for one cycle the distance can be formulated as

$$
I=\frac{V}{2 F}
$$

To gain the length of cut ( $D$ in $\mathrm{mm}$ ) the number of cycles (C) needs to be found. Both are directly proportional to each other. Taking into consideration the incremental distance, with this logic the equation for the number of cycles can be formulated as

$$
C=\frac{D}{2 I}
$$

\section{OSCILLATION METHODS}

Referring to Fig. 2 for method I, both-side equal incremental move or two-side incremental move, the nozzle starts AWJ cutting from point 1 to point 2 with half of the increment and angle $\alpha$ in the direction of cutting. Then the nozzle will again take half of the increment when coming backwards and gain its position at point $3\left(90^{\circ}\right.$ to the workpiece). In this manner it completes one cycle while taking increments in the forward direction of moving as well coming backwards. From point 3 it starts cycle 2 and then the process is repeated in the same way as explained above.

Referring to Fig. 2 for method II, one-side incremental move, it can be seen that this method is very similar to

\section{Comparison (Smooth Zone) between Straight Cut and Oscillation Cut for MS20}

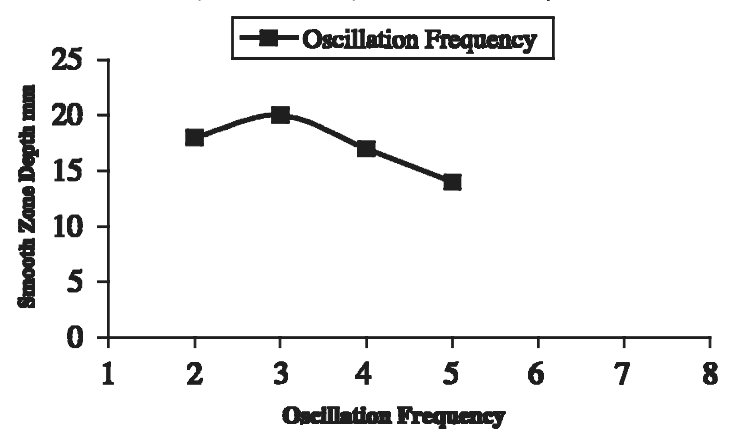

Fig. 3 Comparison between the oscillation frequency and the smooth zone depth

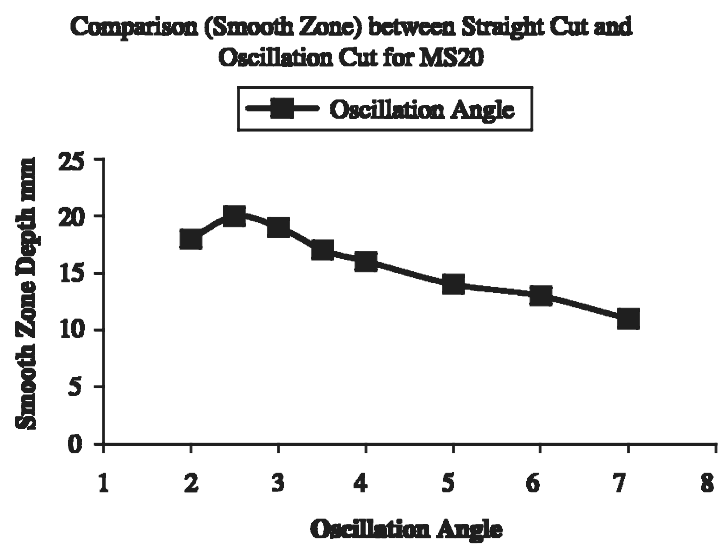

Fig. 4 Comparison between the oscillation angle and the smooth zone depth

method I, the only difference being in the increment. Here the nozzle starts from point 1 and goes to point 2 with only an oscillation angle and no increment, but while coming backwards $\left(90^{\circ}\right.$ to the workpiece) to point 3 it takes increment $\mathrm{I}$, which is equal to the increment taken in method I for one cycle. This is how it completes one cycle and starts a second cycle from point 3 and so on. Both methods were cross-checked using different parameters in the program in both the play and teach modes.

\section{RESULTS}

\subsection{Comparisons between the oscillation frequency and angle and the smooth zone depth}

It was observed that as the oscillation frequency and angle increase the smooth zone depth increases, but after an oscillation frequency of 3 and angle of $2.5^{\circ}$ it decreases (Figs 3 and 4).

\section{CONCLUSIONS}

The following conclusions can be made from this study:

1. The surface finish can be significantly increased with the help of an oscillating cutting nozzle.

2. The surface roughness can be improved by more than 200 per cent using these oscillation cutting techniques.

3. There was a minor difference of 10 per cent in the surface finish in methods I and II in the $X$ direction and method II was found to be superior to method I.

4. The optimum oscillation frequency and oscillation angle were found to be 3 and $2.5^{\circ}$ respectively in both directions for different methods.

5. The kerf width increases with an increase in oscillation frequency and oscillation angle.

6. The surface quality is highly dependent on the method of cutting and motion mechanism adopted. 


\section{REFERENCES}

1 Siores, E., Wong, W. C. K., Chen, L. and Wager, J. G. Enhancing abrasive waterjet cutting of ceramics by head oscillation techniques. Ann. CIRP, January 1996, 45, 327-330.

2 Niu, M., Fukunishi, Y. and Sawamura, T. Control of striated roughness on the surface cut by abrasive water jet. Jetting Technol., 1996, 769-777 (BHR Group).

3 Hashish, M. The effect of beam angle in abrasive waterjet machining. J. Engng for Industry, February 1993, 115, 51-57.

4 Kiyono, F. and Saito, T. Basic concept for the design of an oscillating jets nozzle. Jetting Technol., 1998, 143-157 (BHR Group).

5 Arola, D. and Ramulu, M. Material removal in abrasive waterjet machining of metals: surface integrity and texture. Wear, 1997, 210, 50-58.

6 Guo, N. S., Louis, H. and Meier, G. Surface structure and kerf geometry in abrasive water jet cutting: formation and optimization. In 7th American Water Jet Conference, Seattle, Washington, 28-31 August 1993, paper 1, pp. $1-25$.

7 Hashish, M. On modelling of surface waviness produced by abrasive-waterjets. In Proceedings of 11 th International Conference on Jet Cutting Technology, St Andrews, Scotland, 8-10 September 1992, pp. 17-34.

8 Kovacevic, R., Hashish, M., Mohan, R., Ramulu, M., Kim, T. J. and Geskin, E. S. State of art of research and development in abrasive waterjet machining. Trans. ASME, J. Mfg Sci. Engng, November 1997, 119, 776-785.

9 Ohlsson, L., Powell, J. and Magnusson, C. Mechanism of striation formation in abrasive waterjet cutting. In 13th International Conference on Jetting Technology, 1997, pp. 151-164.

10 Verma, A. P. and Lal, G. K. A theoretical study of erosion phenomenon in abrasive jet machining. Trans. ASME, J. Mfg Sci. Engng, November 1996, 118, 564-570. 
Copyright $\odot 2003$ EBSCO Publishing 